\title{
Impact of cardiac catheterization timing and contrast media dose on acute kidney injury after cardiac surgery
}

Wuhua Jiang ${ }^{1,2,3 \dagger}$, Jiawei $Y u^{1,2,3 \dagger}$, Jiarui $X u^{1,2,3}$, Bo Shen ${ }^{1,2,3}$, Yimei Wang ${ }^{1,2,3}$, Zhe Luo ${ }^{6}$, Chunsheng Wang ${ }^{7}$, Xiaoqiang Ding ${ }^{1,2,3,4,5}$ and Jie Teng ${ }^{1,2,3,45^{*}}$ (I)

\begin{abstract}
Background: The association between pre-operative cardiac catheterization and cardiac surgery associated acute kidney injury (CSA-AKI) has been reported inconsistently. The purpose of this study is to evaluate the effect of the catheterization timing and contrast media dose on the incidence of postoperative acute kidney injury.

Methods: Patients who underwent cardiac catheterization and cardiac surgery successively from January 2015 to December 2015 were prospectively enrolled in this study. The primary outcome was CSA-AKI which was defined as the Kidney Disease: Improving Global Outcomes Definition and Staging (KDIGO) criteria. Univariate analysis and multivariate regression were performed to identify the predictors for CSA-AKI. Baseline characteristics were balanced with propensity score method for better adjustment.

Results: A total of 1069 consecutive eligible patients were enrolled into this study. The incidence of CSA-AKI and AKI requiring renal replacement therapy (AKI-RRT) were 38.5\% (412/1069) and 1.9\% (20/1069) respectively.

Preoperative estimated glomerular filtration rate less than $60 \mathrm{~mL} / \mathrm{min} / 1.73 \mathrm{~m}^{2}(\mathrm{OR}=2.84395 \% \mathrm{Cl} 1.374-5.882)$, the time interval between catheterization and surgery $\leq 7$ days $(\mathrm{OR}=2.546,95 \% \mathrm{Cl} 1.548-4.189)$ and the dose of contrast media $(C M)>240 \mathrm{mg} / \mathrm{kg}(\mathrm{OR}=2.490,95 \% \mathrm{Cl} 1.392-4.457)$ were identified as predictors for CSA-AKI. In the patients with the dose of CM $>240 \mathrm{mg} / \mathrm{kg}$, the incidence of CSA-AKI was higher in patients who underwent cardiac catheterization $\leq 7$ days before cardiac surgery than in those of $>7$ days before cardiac surgery $(39.4 \% \mathrm{vs} .28 .8 \%$, $p=0.025$ ). The longer interval of more than 7 days was revealed to be inversely associated with CSA-AKI through logistic regression $(\mathrm{OR}=0.579,95 \% \mathrm{Cl} 0.337-0.994)$.

Conclusion: Catheterization within 7 days of cardiac surgery and a dose of CM $>240 \mathrm{mg} / \mathrm{kg}$ were associated with the onset of CSA-AKI. For patients who received a dose of CM $>240 \mathrm{mg} / \mathrm{kg}$, postponing the cardiac surgery is potentially beneficial to reduce the risk of CSA-AKI.
\end{abstract}

Keywords: Acute kidney injury, Cardiac surgery, Cardiac catheterization, Contrast media

\section{Background}

Acute kidney injury (AKI) is one of the prevalent complications after cardiac surgery with reported incidences over $30 \%$ and associated higher mortality and excessive medical resource consumption [1-5]. Since no effective therapy is available to reverse the mechanism of AKI,

\footnotetext{
* Correspondence: tengjie69@163.com; teng.jie@zsxmhospital.com

'Wuhua Jiang and Jiawei Yu contributed equally to this work.

'Department of Nephrology, Zhongshan Hospital, Shanghai Medical College,

Fudan University, No 180 Fenglin Rd, Shanghai 200032, China

${ }^{2}$ Shanghai Institute of Kidney and Dialysis, Shanghai, China

Full list of author information is available at the end of the article
}

early identification and modification of risk factors are necessary to prevent AKI [2].

Cardiac catheterization is one of the common pre-operative examinations. This procedure is aimed to screen the patients with high risk of coronary artery disease and provide clinicians with multiple cardiac surgical procedure alternatives. Recently, the association between pre-operative cardiac catheterization and postoperative acute kidney injury has been reported in several studies [6-11]. However, few of these studies interrogate both the interval between catheterization and surgery and the

(c) The Author(s). 2018 Open Access This article is distributed under the terms of the Creative Commons Attribution 4.0 International License (http://creativecommons.org/licenses/by/4.0/), which permits unrestricted use, distribution, and reproduction in any medium, provided you give appropriate credit to the original author(s) and the source, provide a link to the Creative Commons license, and indicate if changes were made. The Creative Commons Public Domain Dedication waiver (http://creativecommons.org/publicdomain/zero/1.0/) applies to the data made available in this article, unless otherwise stated. 
dose of contrast media (CM) simultaneously [11]. Moreover, these studies reported conflicting findings.

Accordingly, the purpose of this study is to identify the association between timing of catheterization, the dose of contrast media and postoperative AKI. The hypothesis is a shorter interval between catheterization and surgery and a higher dose of $\mathrm{CM}$ used in the catheterization are associated with increased incidence of AKI after surgery.

\section{Methods}

\section{Study population}

This study was based on the Zhongshan Cardiac Surgery Database, and the requirement for informed consent was waived by the ethical board from Zhongshan Hospital given the retrospective design. Patients who underwent cardiac catheterization and valve/ coronary artery bypass grafting (CABG)/valve + CABG at Fudan University Zhongshan Hospital in 2015 were included in this study. Patients with prior dialysis or underwent catheterization in other hospital and referred for surgery were excluded. Those who underwent urgent or salvage surgery were excluded as well. A dataset of 1069 eligible patients formed the study population. In case that more than one cardiac surgical procedure performed during the same hospitalization, only the data on the first surgery was considered. The datasets used and/ or analysed during the current study are available from the corresponding author on reasonable request.

\section{Catheterization protocol}

All patients in the dataset received iso-osmolar CM (Iodixanol, Visipaque ${ }^{\circ}, \mathrm{GE}$ Healthcare, Ireland) at iodine concentration of $320 \mathrm{mg} / \mathrm{ml}$. The amount of $\mathrm{CM}$ was expressed in terms of milligrams per kilogram $(\mathrm{mg} / \mathrm{kg})$ to account for the iodine dose in different patients. Known nephrotoxic medications are discontinued $24 \mathrm{~h}$ before catheterization. Besides, adequate hydration of intravenous normal saline before angiography $(1 \mathrm{ml} / \mathrm{kg} \cdot \mathrm{h}$ for $12 \mathrm{~h}$ ), limiting of $\mathrm{CM}$ volume and intravenous sodium bicarbonate after angiography are routinely executed as standard protocol.

\section{Data definitions and endpoints}

The interval time between the catheterization and the surgery was defined (days). Operation on the same day of the angiography was coded as interval 0 . The cutoff value (7 days) of the interval derived from previous study [12] suggesting that, after being exposed contrast, renal function usually returns to preexisting levels within 7 days. The cutoff value for high contrast dose was determined with the receiving operating curve that had the maximal sum of sensitivity and specificity. In this study, it was found to be $240 \mathrm{mg} / \mathrm{kg}$.
The primary endpoint was the occurrence of cardiac surgery associated acute kidney injury (CSA-AKI), which was defined as Kidney Disease: Improving Global Outcomes Definition and Staging (KDIGO) criteria [13] as any of the following: increase in serum creatinine $(\mathrm{SCr})$ by $\geq 0.3 \mathrm{mg} / \mathrm{dL}(\geq 26.5 \mu \mathrm{mol} / \mathrm{L})$ within $48 \mathrm{~h}$; or increase in $\mathrm{SCr}$ to $\geq 1.5$ times baseline that is known or presumed to have occurred within the prior 7 days or urine volume $<0.5 \mathrm{~mL} / \mathrm{kg}$ per hour for $6 \mathrm{~h}$. AKI was classified as KDIGO criteria: grade 1: post-op serum creatinine 1.51.9 times baseline or an increase in serum creatinine $\geq 26.5 \mu \mathrm{mol} / \mathrm{L}$ or a urine output $<0.5 \mathrm{ml} / \mathrm{kg} / \mathrm{h}$ for 6 $12 \mathrm{~h}$; grade 2: post-op serum creatinine $2.0-2.9$ times baseline or a urine output $<0.5 \mathrm{ml} / \mathrm{kg} / \mathrm{h}$ for $\geq 12 \mathrm{~h}$; and grade 3: post-op serum creatinine 3 times baseline or increase in serum creatinine to $\geq 353.6 \mu \mathrm{mol} / \mathrm{L}$ or initiation of renal replacement therapy or a urine output $<0.3 \mathrm{ml} / \mathrm{kg} / \mathrm{h}$ for $\geq 24 \mathrm{~h}$ OR anuria for $\geq 12 \mathrm{~h}$. The indications for renal replacement therapy (RRT) were metabolic abnormalities (acidosis, hyperkalemia), anuria, and fluid overload. The secondary endpoint was the in-hospital mortality.

Other perioperative variables in the present study included gender, age, comorbidities, preoperative cardiac function condition stratified with New York Heart Association (NYHA) classification, baseline serum creatinine and estimated glomerular filtration rate (eGFR) calculated with CKD-EPI formulae, procedures, cardiopulmonary bypass $(\mathrm{CPB})$ duration (coded zero in patients operated without $\mathrm{CPB}$ ) and erythrocyte transfusion, provided that they were used during surgery or the following $24 \mathrm{~h}$. All data were checked twice by professional personnel before being admitted to the dataset.

\section{Statistics analysis}

Continuous variables were expressed as the mean \pm standard deviation (SD) and analyzed by unpaired t-tests, with Welch adjustment when necessary. Continuous variables that violated the normality assumption were expressed as median (interquartile range) and analyzed by a Mann-Whitney $U$ test. Categorical variables were expressed as numbers (n) and percentage (\%) and were analyzed by the Pearson $\chi^{2}$ test or the Fisher exact test whenever appropriate.

Univariate analysis was performed to identify variables associated with CSA-AKI and those with $P<0.05$ were included in the multivariate regression analysis to identify the independent risk factors for CSA-AKI. Propensity scores were later used as a way for better adjustment of the preoperative differences and control for selection bias. An adjusted logistic regression model was developed with variables that showed a $P$ value $<0.05$ in the univariate analysis. Significant level was considered with $P<0.05$. Statistical analyses were performed by SPSS statistics for Windows (Version 24.0. IBM Corp, Armonk, NY). 


\section{Results}

Baseline clinical and catheterization characteristics Of 1069 eligible patients studied, 412 (38.5\%) developed CSA-AKI according to KDIGO criterion. Among the AKI patients, the incidence of stage 2 AKI was $12.9 \%$ (53/412) and $6.1 \%(25 / 412)$ for stage 3 AKI. Renal replacement therapies were performed in $20(1.9 \%)$ patients. Patients were stratified by the interval between catheterization and surgery into two groups, and their baseline characteristics are shown in Table 1 . Most of the patients (83.1\%) received surgery within 7 days. Compared with patients who underwent surgery after $>7$ days, those undergoing surgery within 7 days were younger $(61.3 \pm 8.1$ vs. $63.9 \pm$ 8.3 years, $p<0.001)$ and were less frequently male $(60.6 \%$ vs. $71.3 \%, p<0.001)$, comorbid fewer hypertension $(41.0 \%$ vs. $63.0 \%, p<0.001)$ and diabetes mellitus (13.1\% vs.30.9,\% $p<0.001)$ but more NYHA $3-4$ (77.3\% vs. $65.2 \%, p<0.001)$. The hemoglobin, albumin, serum creatinine and eGFR were similar. There were no significant differences in the amount of CM dose used in both cohorts. More valve surgery (77.9\% vs.22.1\%, $p<0.001)$ and $\mathrm{CPB}(79.4 \%$ vs.31.5\%, $p<0.001)$ whereas less CABG (17.0\% vs.72.4\%, $p<0.001)$ were performed in the shorter interval cohort.

Concerning the endpoints, the incidence of AKI in the shorter interval cohort was twofold higher than the longer interval cohort $(42.1 \%$ vs. $21.0 \%, \mathrm{p}<0.001)$ whereas the incidence of AKI requiring renal replacement therapy (AKI-RRT) and in-hospital mortality were similar. The intensive care unit (ICU) stay was similar while the hospital stay in the shorter interval cohort was longer than the longer interval cohort (14 vs. 12 days, $p<0.001)$.

\section{Univariate analysis}

Univariate analysis was performed to identify variables associated with CSA-AKI (Table 2). Male gender, advanced NYHA classification, higher preoperative serum creatinine, more frequently valve surgery and less CABG performed, more frequently $\mathrm{CPB}$ and erythrocyte transfusion performed, and longer $\mathrm{CPB}$ duration was associated with the occurrence of CSA-AKI. Especially, eGFR less than $60 \mathrm{ml} / \mathrm{min} / 1.73 \mathrm{~m}^{2}$, shorter interval between catheterization and surgery and CM dose $>240 \mathrm{ml} / \mathrm{kg}$ increased CSA-AKI as well. Regarding secondary endpoint, mortality in the AKI patients was higher than those without AKI $(0.7 \%$ vs. $0, p=0.029)$. The length of ICU (47 vs. $32 \mathrm{~h}, p<0.001)$ and hospital stay (13 vs. 12 days, $\mathrm{p}<0.001)$ in the AKI patients were higher than those without AKI.

\section{Multivariate analysis}

Multivariate analysis was performed to identify risk factors associated with CSA-AKI from the pool of variables that showed a $P$ value $<0.05$ in the univariate analysis (Table 3). Male gender (odds ration $[\mathrm{OR}]=1.615$, 95\%
1.223-2.132), advanced NYHA classification (3-4) (OR $=1.683,95 \% 1.225-2.311)$, combined surgery $(\mathrm{OR}=$ 2.595, 95\% CI 1.376-4.892), eGFR less than $60 \mathrm{ml} / \mathrm{min} /$ $1.73 \mathrm{~m}^{2}(\mathrm{OR}=1.654,95 \%$ CI 1.076-2.542), shorter interval between catheterization and surgery $(\mathrm{OR}=2.184$, 95\%1.416-3.368) and CM dose $>240 \mathrm{ml} / \mathrm{kg}(\mathrm{OR}=1.346$, 95\%1.013-1.788) were found to be independent risk factors for CSA-AKI.

Propensity score method was applied to control the selection bias related to covariates and better adjust the preoperative differences, and an adjusted logistic regression model was developed with variables that showed a $\mathrm{P}$ value $<0.05$ in the univariate analysis. Preoperative estimated glomerular filtration rate less than $60 \mathrm{~mL} / \mathrm{min}$ (adjusted $\mathrm{OR}=2.84395 \% \mathrm{CI} 1.374-5.882$ ), the time interval between catheterization and surgery $\leq 7$ days (adjusted $\mathrm{OR}=2.546,95 \%$ CI $1.548-4.189$ ) and dose of $\mathrm{CM}>240 \mathrm{mg} / \mathrm{kg}$ (adjusted $\mathrm{OR}=2.490$, 95\% CI $1.392-$ 4.457) were identified as predictors for CSA-AKI (Table 3).

\section{Subgroup analysis}

The subgroup analysis was performed to elucidate the impact that shorter interval had on the development of CSA-AKI in the subjects exposed to higher dose CM (> $240 \mathrm{ml} / \mathrm{kg}$ ). The incidence of CSA-AKI was higher in shorter interval patients than those had a longer interval (39.4\% vs. $28.8 \%, p=0.025)$. The longer interval of more than 7 days was revealed to be inversely associated with CSA-AKI (OR = 0.579, 95\% CI 0.337-0.994) (Table 4).

In the subgroup of patients underwent on-pump surgery, 41.9\% (319/762) developed AKI. Logistic regression showed male gender $(\mathrm{OR}=1.763,95 \%$ CI 1.293-2.404), shorter interval $(\leq 7 \mathrm{~d})(\mathrm{OR}=2.427,95 \%$ CI $1.270-4.637)$ and NYHA classification $3-4 \quad(\mathrm{OR}=1.768,95 \% \mathrm{CI}$ 1.187-2.631) were found associated with the development of CSA-AKI (Table 5).

\section{Discussion}

The main findings of current study are (1) AKI after catheterization and cardiac surgery is prevalent, according to KDIGO definition, with the incidence of $38.5 \%$; (2) the mortality of patients with AKI is significantly higher than those without AKI; (3) lower baseline eGFR, shorter interval between catheterization and cardiac surgery $(<7$ days) and higher $\mathrm{CM}$ dose $(>240 \mathrm{mg} / \mathrm{kg})$ used are associated with the development of CSA-AKI; (4) in the patients receiving higher dose of $\mathrm{CM}$, postponing cardiac surgery is possibly protective for reducing AKI risk.

Postoperative acute kidney injury remains one of the major complications with worse prognosis [3, 5]. Effective prevention is predominantly dependent on the early identification of risk factors. Many risk factors have been revealed associating with CSA-AKI [1]. However, few of 
Table 1 Patients Perioperative Characteristics Stratified by the Interval between Coronary Angiography and Cardiac Surgery

\begin{tabular}{|c|c|c|c|}
\hline & $\leq 7$ days $(N=888)$ & $>7$ days $(N=181)$ & $P$ \\
\hline \multicolumn{4}{|l|}{ Demographic data } \\
\hline Male & $538(60.6)$ & 129(71.3) & 0.007 \\
\hline Age (year) & $61.3 \pm 8.1$ & $63.9 \pm 8.3$ & $<0.001$ \\
\hline \multicolumn{4}{|l|}{ Medical history } \\
\hline Hypertension & $364(41.0)$ & $114(63.0)$ & $<0.001$ \\
\hline DM & 116(13.1) & $56(30.9)$ & $<0.001$ \\
\hline NYHA classification 3-4 & $686(77.3)$ & 118(65.2) & $<0.001$ \\
\hline \multicolumn{4}{|l|}{ Laboratory values } \\
\hline Hemoglobin (g/L) & $131.5 \pm 15.1$ & $130.9 \pm 141.3$ & 0.685 \\
\hline Albumin(g/L) & $40.2 \pm 3.5$ & $39.8 \pm 3.7$ & 0.184 \\
\hline \multicolumn{4}{|l|}{ Kidney function } \\
\hline Serum creatinine (mg/dl) & $81.9 \pm 24.5$ & $85.8 \pm 25.0$ & 0.055 \\
\hline eGFR $\left(\mathrm{ml} / \mathrm{min} / 1.73 \mathrm{~m}^{2}\right)$ & $83.8 \pm 19.5$ & $81.8 \pm 20.8$ & 0.227 \\
\hline $\mathrm{eGFR}<60 \mathrm{ml} / \mathrm{min} / 1.73 \mathrm{~m}^{2}$ & $80(9.1)$ & 24(13.9) & 0.069 \\
\hline \multicolumn{4}{|l|}{ Angiographic values } \\
\hline Interval between angiography and surgery (day) & $3.2(1.9)$ & $9.7(2.7)$ & $<0.001$ \\
\hline${ }^{\mathrm{a} C}$ Contrast media dose $(\mathrm{ml} / \mathrm{kg})$ & $280(231,349)$ & $285(246,342)$ & 0.198 \\
\hline \multicolumn{4}{|l|}{ Surgical data } \\
\hline Valve & $692(77.2)$ & $40(22.1)$ & $<0.001$ \\
\hline CABG & $151(17.0)$ & $131(72.4)$ & $<0.001$ \\
\hline Valve \& CABG & $45(5.1)$ & $10(5.5)$ & 0.326 \\
\hline $\mathrm{CPB}$ & $705(79.4)$ & $57(31.5)$ & $<0.001$ \\
\hline${ }^{\mathrm{a} C P B}$ time (min) & $100(75,127)$ & $90(70,119)$ & 0.106 \\
\hline${ }^{b}$ Erythrocyte transfusion & $441(49.6)$ & $75(41.4)$ & 0.149 \\
\hline \multicolumn{4}{|l|}{ Prognosis } \\
\hline AKI & $374(42.1)$ & $38(21.0)$ & $<0.001$ \\
\hline KDIGO 1 & $305(34.3)$ & 29(16.0) & $<0.001$ \\
\hline KDIGO 2 & $45(5.1)$ & $8(4.5)$ & 0.286 \\
\hline KDIGO 3 & $24(2.7)$ & $1(0.6)$ & $<0.001$ \\
\hline RRT & $16(1.8)$ & $4(2.2)$ & 0.762 \\
\hline In-hospital mortality & $2(0.2)$ & $1(0.6)$ & 0.427 \\
\hline a'Length of ICU stay (day) & $40(22,64)$ & $42(22,70)$ & 0.861 \\
\hline aLength of hospital stay (day) & $14(11,18)$ & $12(11,15)$ & $<0.001$ \\
\hline
\end{tabular}

AKI Acute kidney injury, DM diabetes mellitus, NYHA New York Heart Association, eGFR estimated glomerular filtration rate, calculated by CKD-EPI formulae, CABG coronary artery bypass grafting, $C P B$ cardiopulmonary bypass, $K D I G O$ kidney disease: improving global outcomes, $R R T$ renal replacement therapy, ICU intensive care unit

$P$-values are the results of unpaired t-test or Mann-Whitney $U$ test for continuous variables, and $\times 2$ test or Fisher's exact test for categorical variables ${ }^{a}$ The values are expressed as the median (IQR)

${ }^{b}$ The amount of erythrocyte transfusion refers to the amount of transfusion during both intraoperative and postoperative on the day of surgery

them are modifiable, but their clinical implications are significant.

The American College of Cardiology/American Heart Association guidelines for the management of patients with valve heart disease has a class I level of recommendation to perform angiography in patients scheduled for valve surgery [14]. While catheterizations are prevalently performed before cardiac surgery to screen potential coronary disease and indicate appropriate surgery, the adverse effect CM have on the kidney, which is known as contrast induced nephropathy $(\mathrm{CIN})$, requires concern.

Among multiple mechanisms contributing to CIN, renal ischemia, particularly in the medulla, reactive oxygen species formation, reduction of nitric oxide production, and tubular epithelial and vascular endothelial injury are reported frequently $[15,16]$. Patients with pre-existing renal 
Table 2 Perioperative univariate analysis of AKI

\begin{tabular}{|c|c|c|c|}
\hline & No AKI $(N=657)$ & AKI $(N=412)$ & $P$ \\
\hline \multicolumn{4}{|l|}{ Demographic data } \\
\hline Male & $394(60.0)$ & $273(66.3)$ & 0.039 \\
\hline Age (year) & $61.8 \pm 8.1$ & $61.7 \pm 8.3$ & 0.936 \\
\hline \multicolumn{4}{|l|}{ Medical history } \\
\hline Hypertension & $294(44.7)$ & $184(44.7)$ & 0.977 \\
\hline DM & $102(15.5)$ & $70(17.0)$ & 0.526 \\
\hline NYHA classification 3-4 & $465(70.8)$ & 339(82.3) & $<0.001$ \\
\hline \multicolumn{4}{|l|}{ Laboratory values } \\
\hline Hemoglobin (g/L) & $131.6 \pm 14.2$ & $131.1 \pm 16.1$ & 0.555 \\
\hline Albumin(g/L) & $40.3 \pm 3.6$ & $40.0 \pm 3.6$ & 0.187 \\
\hline \multicolumn{4}{|l|}{ Kidney function } \\
\hline Serum creatinine (mg/dl) & $81.3 \pm 25.1$ & $84.5 \pm 23.8$ & 0.038 \\
\hline eGFR $\left(\mathrm{ml} / \mathrm{min} / 1.73 \mathrm{~m}^{2}\right)$ & $83.9 \pm 18.7$ & $82.8 \pm 21.3$ & 0.395 \\
\hline $\mathrm{eGFR}<60 \mathrm{ml} / \mathrm{min} / 1.73 \mathrm{~m}^{2}$ & $54(8.4)$ & $50(12.1)$ & 0.048 \\
\hline \multicolumn{4}{|l|}{ Angiographic values } \\
\hline Interval between angiography and surgery (day) & $4.5 \pm 3.3$ & $4.1 \pm 3.0$ & 0.048 \\
\hline${ }^{\mathrm{a} C o n t r a s t ~ m e d i a ~ d o s e ~(m l / k g) ~}$ & $285(243,341)$ & $280(238,347)$ & 0.696 \\
\hline Contrast media dose> 240 (ml/kg) & $434(66.1)$ & $302(73.3)$ & 0.040 \\
\hline \multicolumn{4}{|l|}{ Surgical data } \\
\hline Valve & $427(65.0)$ & $305(74.0)$ & $<0.001$ \\
\hline CABG & 205(31.2) & $77(18.7)$ & $<0.001$ \\
\hline Valve \& CABG & 25(3.8) & $30(7.3)$ & 0.026 \\
\hline CPB utilization & $443(67.3)$ & $319(77.4)$ & $<0.001$ \\
\hline${ }^{\mathrm{a}} \mathrm{CPB}$ time (min) & $83(67,109)$ & $100(77,132)$ & $<0.001$ \\
\hline${ }^{b}$ Erythrocyte transfusion & 296(44.6) & $223(54.1)$ & 0.04 \\
\hline \multicolumn{4}{|l|}{ Prognosis } \\
\hline RRT & $3(0.5)$ & $17(4.1)$ & $<0.001$ \\
\hline In-hospital mortality & 0 & $3(0.7)$ & 0.029 \\
\hline aLength of ICU stay (day) & $32(21,63)$ & $47(26,90)$ & $<0.001$ \\
\hline aLength of hospital stay (day) & $12(10,15)$ & $13(11,17)$ & 0.003 \\
\hline
\end{tabular}

AKI acute kidney injury, DM diabetes mellitus, NYHA New York Heart Association, eGFR estimated glomerular filtration rate, calculated by CKD-EPI formulae, CABG coronary artery bypass grafting, $C P B$ cardiopulmonary bypass, $R R T$ renal replacement therapy, ICU intensive care unit

$P$-values are the results of unpaired t-test or Mann-Whitney $U$ test for continuous variables, and $\times 2$ test or Fisher's exact test for categorical variables

${ }^{\mathrm{a}}$ The values are expressed as the median (IQR)

${ }^{\mathrm{b}}$ The amount of erythrocyte transfusion refers to the amount of transfusion during both intraoperative and postoperative on the day of surgery

impairment with reduced nephron mass are susceptible to the influence of CM $[17,18]$. The decline in kidney function usually occurs 1 to 3 days after the procedure. Renal function usually returns to pre-existing levels within 7 days [12]. Assuming that kidney was compromised by "double strike" from cardiac surgery associated adverse effect like hemodynamic instability and inflammatory reaction when kidney function has not recovered, the risk of CSA-AKI increases theoretically.

As modifiable features, the interval between catheterization and surgery as well as the CM dose and their association with CIN have been targeted for preventing
AKI after surgery $[6-8,10,11,19,20]$. Conflicting data have been reported. Several authors proposed that closer succession between two procedures have an adverse impact on the development of CSA-AKI $[6,8,10,11]$, whereas other authors claimed the risk of CSA-AKI is not influenced by the time interval [7, 21]. The main differences across the studies are attributed to variant AKI definitions and different surgical procedures. A meta-analysis encompassing nine studies showed that the time interval of 1 day or less between CAG and on-pump cardiac surgery was significantly associated with increased risk of AKI [22]. 
Table 3 Multivariate regression of risk factors for CSA-AKI

\begin{tabular}{|c|c|c|c|c|c|c|}
\hline & \multirow[b]{2}{*}{ OR } & \multicolumn{2}{|l|}{ Unadjusted } & \multirow[b]{2}{*}{ OR } & \multicolumn{2}{|l|}{ Adjusted } \\
\hline & & $95 \% \mathrm{Cl}$ & $P$ value & & $95 \% \mathrm{Cl}$ & $P$ value \\
\hline Male & 1.615 & $1.223-2.132$ & 0.001 & 1.568 & $0.871-2.821$ & 0.133 \\
\hline Interval $\leq 7 d$ & 2.184 & $1.416-3.368$ & $<0.001$ & 2.546 & $1.548-4.189$ & $<0.001$ \\
\hline Contrast used> $240 \mathrm{mg} / \mathrm{kg}$ & 1.346 & $1.013-1.788$ & 0.041 & 2.490 & $1.392-4.457$ & 0.002 \\
\hline NYHA 3-4 & 1.683 & $1.225-2.311$ & 0.001 & 1.689 & $0.971-2.938$ & 0.063 \\
\hline Valve \& CABG & 2.595 & $1.376-4.892$ & 0.003 & 2.825 & $0.781-10.223$ & 0.114 \\
\hline $\mathrm{eGFR}<60 \mathrm{ml} / \mathrm{min} / 1.73 \mathrm{~m}^{2}$ & 1.654 & $1.076-2.542$ & 0.022 & 2.843 & $1.374-5.882$ & 0.005 \\
\hline
\end{tabular}

CSA-AKI cardiac surgery associated acute kidney injury, OR odds ration, Cl confidence interval, NYHA New York Heart Association, CABG coronary artery bypass grafting, eGFR estimated glomerular filtration rate, calculated by CKD-EPI formulae

Both Interval $\leq 7 \mathrm{~d}$ and Contrast used $>240 \mathrm{mg} / \mathrm{kg}$ are revealed as predictors in the unadjusted and adjusted logistic regression analysis

Another recent study, in which AKI was defined as KDIGO criteria, showed that on-pump CABG performed within 7 days after catheterization was a predictor of postoperative AKI [19]. Consistent with this finding, a similar outcome resulted through the subgroup analysis in the present study. In the patients had $\mathrm{CPB}$ during their valve or CABG, catheterization within 7 days of surgery was a predictor for CSA-AKI.

The amount and type of $\mathrm{CM}$ used during catheterization have also been reported to affect the incidence of CIN as well. The nephrotoxic effect of iodinated CM may be proportional to dose. However, there is no evidence of a dose-toxicity relationship when administered at usual diagnostic dose [23]. Administration of higher $\mathrm{CM}$ volumes is associated with increased CIN rate in patients with chronic kidney disease or diabetes mellitus [24-26]. The osmolality and viscosity of the CM have been reported to participate in their renal toxicity $[27,28]$. With routine angiography protocol (see Methods), the amount of CM used in the patients in our institute is limited. The CM used in present study population is iodixanol, a non-ionic iso-osmolar CM, which has been shown to have the lowest associated risk of CIN and mortality $[29,30]$. However, in the present study, a higher dose of CM remained to be an independent predictor of CSA-AKI. In the subgroup consisted of patients received CM dose $>240 \mathrm{mg} / \mathrm{kg}$, the prolonged interval before surgery was inversely associated with the development of CSA-AKI. This result has the clinical implication. A higher dose of CM are usually administrated in patients whose underlying heart disease are complex and more

Table 4 Multivariate analysis for CSA-AKI in the patients who underwent angiography with contrast used $>240 \mathrm{mg} / \mathrm{kg}$

\begin{tabular}{llll}
\hline & OR & $\mathrm{Cl}$ & $P$ value \\
\hline Interval $>7 \mathrm{~d}$ & 0.579 & $0.337-0.994$ & 0.048 \\
eGFR<60 ml/min/1.73 m2 & 2.637 & $1.186-5.864$ & 0.017 \\
\hline
\end{tabular}

CSA-AKI cardiac surgery associated acute kidney injury, OR odds ration, $\mathrm{Cl}$ confidence interval, eGFR estimated glomerular filtration rate, calculated by CKD-EPI formulae

Subgroup analysis revealed the interval between angiography and surgery $>$

7 days is negatively associated with CSA-AKI precise diagnosis and evaluation by high-quality angiography are needed. These patients can be more vulnerable to the successive strike of complicated surgery, which by itself increases the risk of AKI.

Based on the findings, the current study has clinical significance. Patients who underwent cardiac surgery within 7 days are at higher risk of developing CSA-AKI. Especially when the patient has moderate or worse preoperative kidney dysfunction or receiving a higher dose of $\mathrm{CM}$ during the catheterization, postponing cardiac surgery to more than 7 days will be potentially beneficial to prevent post-operative AKI.

The main limitation of this study is that it is an observational trial. The hypothesis that catheterization timing and CM dose are associated with CSA-AKI has been generated in this study, whereas the causality between them shall be drawn deliberately. In spite of a single center study, the propensity score was used to correct for selection bias and baseline difference. Moreover, the individualized dose of $\mathrm{CM}$ was expressed in terms of iodine concentration/patient body weight to make it comparable with other iodinate $\mathrm{CM}$.

\section{Conclusion}

The current study showed catheterization within 7 days of cardiac surgery, a dose of contrast media over $240 \mathrm{mg} / \mathrm{kg}$ and preoperative eGFR less than $60 \mathrm{ml} / \mathrm{min} /$ $1.73 \mathrm{~m}^{2}$ were associated with increased risk of CSA-AKI. The findings suggest that delaying elective cardiac

Table 5 Multivariate analysis for CSA-AKI in the patients who underwent on-pump surgery

\begin{tabular}{llll}
\hline & OR & $95 \% \mathrm{Cl}$ & $P$ value \\
\hline Male gender & 1.763 & $1.293-2.404$ & $<0.001$ \\
Interval $\leq 7 \mathrm{~d}$ & 2.427 & $1.270-4.637$ & 0.007 \\
NYHA 3-4 & 1.768 & $1.187-2.631$ & 0.005 \\
\hline $\begin{array}{l}\text { CSA-AKI cardiac surgery associated acute kidney injury, OR odds ration, } \mathrm{Cl} \\
\text { confidence interval, NYHA New York heart association classification }\end{array}$ \\
$\begin{array}{l}\text { Subgroup analysis revealed shorter interval between angiography and surgery } \\
\text { ( } \leq 7 \mathrm{~d}) \text { is associated with CSA-AKI }\end{array}$
\end{tabular}


surgery is potentially beneficial to prevent CSA-AKI, especially in patients with impaired preoperative kidney dysfunction or those receiving a higher dose of CM. It remained to be verified in the future whether these strategies, along with other protocol, can reduce CSA-AKI incidence and improve prognosis.

\section{Abbreviations}

AKI: Acute kidney injury; CABG: Coronary artery bypass grafting; CM: Contrast media; CPB: Cardiopulmonary bypass; DM: Diabetes mellitus; eGFR: Estimated glomerular filtration rate, calculated by CKD-EPI formulae; ICU: Intensive care unit; KDIGO: Kidney Disease: Improving Global Outcomes; NYHA: New York Heart Association; RRT: Renal replacement therapy

\section{Acknowledgements}

We are grateful for the contribution of the study personnel from the department of nephrology, cardiac surgery and critical care for persistent contribution to the maintenance of the cardiac surgery database.

\section{Funding}

The study was funded by the Shanghai Municipal Commission of Health and Family Planning (15GWZK0502), the Science and Technology Commission of Shanghai Municipality (14DZ2260200, the project of Shanghai Key Laboratory of Kidney and Blood Purification) and the Project of Science and Technology Commission of Shanghai Municipality (17140902300)

\section{Availability of data and materials}

The datasets used and/or analysed during the current study are available from the corresponding author on reasonable request.

\section{Authors' contributions}

XD and JT designed and directed the study, YW and JY participated in data collection and maintenance, WJ, JX, BS analyzed the data, WJ, BS interpreted the results and writing. $\mathrm{ZL}$ and $\mathrm{CW}$ participated in reviewing the manuscript, the maintenance of dataset and facilitating the acquisition of data. All authors read and approved the final manuscript.

\section{Ethics approval and consent to participate}

This study was approved by the ethical board from Zhongshan Hospital, Fudan University (Approval Number B2017-039). The requirement for informed consent was waived by the ethical board from Zhongshan Hospital given the retrospective design.

\section{Consent for publication}

Not applicable.

\section{Competing interests}

The authors declare that they have no competing interests.

\section{Publisher's Note}

Springer Nature remains neutral with regard to jurisdictional claims in published maps and institutional affiliations.

\footnotetext{
Author details

${ }^{1}$ Department of Nephrology, Zhongshan Hospital, Shanghai Medical College, Fudan University, No 180 Fenglin Rd, Shanghai 200032, China. ${ }^{2}$ Shanghai Institute of Kidney and Dialysis, Shanghai, China. ${ }^{3}$ Shanghai Medical Center of Kidney, Shanghai, China. ${ }^{4}$ Department of Nephrology, Xiamen Branch, Zhongshan Hospital, Fudan University, Xiamen, China. ${ }^{5}$ Shanghai Key Laboratory of Kidney and Blood Purification, Shanghai, China. ${ }^{6}$ Department of Cardiac Surgery Intensive Care Unit, Zhongshan Hospital, Shanghai Medical College, Fudan University, Shanghai, China. 'Department of Cardiovascular Surgery, Zhongshan Hospital, Shanghai, China.
}

Received: 19 April 2018 Accepted: 27 September 2018

Published online: 05 October 2018

\section{References}

1. Mao H, Katz N, Ariyanon W, Blanca-Martos L, Adybelli Z, Giuliani A, Danesi TH, Kim JC, Nayak A, Neri M, et al. Cardiac surgery-associated acute kidney injury. Cardiorenal Med. 2013;3(3):178-99.

2. Karkouti K, Wijeysundera DN, Yau TM, Callum JL, Cheng DC, Crowther M, Dupuis JY, Fremes SE, Kent B, Laflamme C, et al. Acute kidney injury after cardiac surgery: focus on modifiable risk factors. Circulation. 2009;119(4): 495-502.

3. Rosner MH, Okusa MD. Acute kidney injury associated with cardiac surgery. Clin J Am Soc Nephrol. 2006;1(1):19-32.

4. Loef BG, Epema AH, Smilde TD, Henning RH, Ebels T, Navis G, Stegeman CA Immediate postoperative renal function deterioration in cardiac surgical patients predicts in-hospital mortality and long-term survival. J Am Soc Nephrol. 2005;16(1):195-200.

5. Lassnigg A, Schmidlin D, Mouhieddine M, Bachmann LM, Druml W, Bauer $P$, Hiesmayr M. Minimal changes of serum creatinine predict prognosis in patients after cardiothoracic surgery: a prospective cohort study. J Am Soc Nephrol. 2004;15(6):1597-605.

6. Ranucci M, Ballotta A, Agnelli B, Frigiola A, Menicanti L, Castelvecchio S. Acute kidney injury in patients undergoing cardiac surgery and coronary angiography on the same day. Ann Thorac Surg. 2013;95(2):513-9.

7. Greason KL, Englberger L, Suri RM, Park SJ, Rihal CS, Pislaru SV, Schaff HV. Safety of same-day coronary angiography in patients undergoing elective aortic valve replacement. Ann Thorac Surg. 2011;91(6):1791-6.

8. Mehta RH, Honeycutt E, Patel UD, Lopes RD, Williams JB, Shaw LK, O'Brien SM, Califf RM, Hughes GC, Sketch MJ. Relationship of the time interval between cardiac catheterization and elective coronary artery bypass surgery with postprocedural acute kidney injury. Circulation. 2011;124(11 Suppl): S149-55.

9. Kramer RS, Quinn RD, Groom RC, Braxton JH, Malenka DJ, Kellett MA, Brown JR. Same admission cardiac catheterization and cardiac surgery: is there an increased incidence of acute kidney injury? Ann Thorac Surg. 2010;90(5): 1418-23 1423-1424.

10. Hennessy SA, LaPar DJ, Stukenborg GJ, Stone ML, Mlynarek RA, Kern JA, Ailawadi G, Kron IL. Cardiac catheterization within 24 hours of valve surgery is significantly associated with acute renal failure. J Thorac Cardiovasc Surg. 2010;140(5):1011-7.

11. Medalion B, Cohen H, Assali A, Vaknin AH, Farkash A, Snir E, Sharoni E, Biderman P, Milo G, Battler A, et al. The effect of cardiac angiography timing, contrast media dose, and preoperative renal function on acute renal failure after coronary artery bypass grafting. J Thorac Cardiovasc Surg. 2010; 139(6):1539-44.

12. Barrett BJ, Parfrey PS. Clinical practice. Preventing nephropathy induced by contrast medium. N Engl J Med. 2006;354(4):379-86.

13. Kellum JA, Lameire N. Diagnosis, evaluation, and management of acute kidney injury: a KDIGO summary (part 1). Crit Care. 2013;17(1):204.

14. Nishimura RA, Otto CM, Bonow RO, Carabello BA, Erwin JR, Fleisher LA, Jneid H, Mack MJ, McLeod CJ, O'Gara PT, et al. 2017 AHA/ACC focused update of the 2014 AHA/ACC guideline for the Management of Patients with Valvular Heart Disease: A Report of the American College of Cardiology/American Heart Association Task Force on Clinical Practice Guidelines. J Am Coll Cardiol. 2017:70(2):252-89.

15. Andreucci M, Faga T, Pisani A, Sabbatini M, Michael A. Acute kidney injury by radiographic contrast media: pathogenesis and prevention. Biomed Res Int. 2014;2014:362725.

16. Scoditti E, Massaro M, Montinari MR. Endothelial safety of radiological contrast media: why being concerned. Vasc Pharmacol. 2013;58(1-2):48-53.

17. Hogstrom B, Ikei N. Physicochemical properties of radiographic contrast media, potential nephrotoxicity and prophylaxis. Clin Exp Pharmacol Physiol. 2015;42(12):1251-7.

18. Stacul F, van der Molen AJ, Reimer P, Webb JA, Thomsen HS, Morcos SK, Almen T, Aspelin P, Bellin MF, Clement O, et al. Contrast induced nephropathy: updated ESUR contrast media safety committee guidelines. Eur Radiol. 2011;21(12):2527-41.

19. Kim K, Joung KW, Ji SM, Kim JY, Lee EH, Chung CH, Choi IC. The effect of coronary angiography timing and use of cardiopulmonary bypass on acute kidney injury after coronary artery bypass graft surgery. J Thorac Cardiovasc Surg. 2016;152(1):254-61. 
20. Lee EH, Chin JH, Joung KW, Choi DK, Kim WJ, Lee JB, Hahm KD, Sim JY, Choi IC. Impact of the time of coronary angiography on acute kidney injury after elective off-pump coronary artery bypass surgery. Ann Thorac Surg. 2013:96(5):1635-41.

21. Ozkaynak B, Kayalar N, Gumus F, Yucel C, Mert B, Boyacioglu K, Erentug V. Time from cardiac catheterization to cardiac surgery: a risk factor for acute kidney injury? Interact Cardiovasc Thorac Surg. 2014;18(6):706-11.

22. Hu Y, Li Z, Chen J, Shen C, Song Y, Zhong Q. The effect of the time interval between coronary angiography and on-pump cardiac surgery on risk of postoperative acute kidney injury: a meta-analysis. J Cardiothorac Surg. 2013;8:178.

23. Kodzwa R. Updates to the ACR manual on contrast media. Radiol Technol. 2017;89(2):186-9.

24. Aguiar-Souto P, Ferrante G, Del FF, Barlis P, Khurana R, Di Mario C. Frequency and predictors of contrast-induced nephropathy after angioplasty for chronic total occlusions. Int J Cardiol. 2010;139(1):68-74.

25. Kahn JK, Rutherford BD, McConahay DR, Johnson WL, Giorgi LV, Shimshak TM, Hartzler GO. High-dose contrast agent administration during complex coronary angioplasty. Am Heart J. 1990;120(3):533-6.

26. Kane GC, Doyle BJ, Lerman A, Barsness GW, Best PJ, Rihal CS. Ultra-low contrast volumes reduce rates of contrast-induced nephropathy in patients with chronic kidney disease undergoing coronary angiography. J Am Coll Cardiol. 2008;51(1):89-90.

27. Azzalini L, Spagnoli V, Ly HQ. Contrast-induced nephropathy: from pathophysiology to preventive strategies. Can J Cardiol. 2016;32(2):247-55.

28. Persson PB, Hansell P, Liss P. Pathophysiology of contrast medium-induced nephropathy. Kidney Int. 2005;68(1):14-22.

29. Wang YC, Tang A, Chang D, Lu CQ, Zhang SJ, Ju S. Long-term adverse effects of low-Osmolar compared with Iso-Osmolar contrast media after coronary angiography. Am J Cardiol. 2016;118(7):985-90.

30. McCullough PA, Brown JR. Effects of intra-arterial and intravenous IsoOsmolar contrast medium (Iodixanol) on the risk of contrast-induced acute kidney injury: a meta-analysis. Cardiorenal Med. 2011;1(4):220-34.

Ready to submit your research? Choose BMC and benefit from:

- fast, convenient online submission

- thorough peer review by experienced researchers in your field

- rapid publication on acceptance

- support for research data, including large and complex data types

- gold Open Access which fosters wider collaboration and increased citations

- maximum visibility for your research: over $100 \mathrm{M}$ website views per year

At $\mathrm{BMC}$, research is always in progress.

Learn more biomedcentral.com/submissions 